\title{
Planejamento orçamentário e políticas públicas: explorando uma alternativa de reconciliação pela indução
}

\section{Budget planning and public policies: exploring an alternative of reconciliation by induction}

\author{
VANICE LÍRIO DO VALLE* \\ Universidade Estácio de Sá - UNESA (Brasil) \\ vanicevalle@gmail.com \\ Aprovado/Approved: 28.04.2018 / April $28^{\text {th }}, 2018$
}

Recebido/Received: 15.09 .2017 / September $15^{\text {th }}, 2017$

\section{Resumo}

Cláusulas constitucionais exigem que planejamento e provisão orçamentária precedam as escolhas públicas. Apesar disso, políticas públicas no Brasil são raramente traduzidas de maneira adequada no orçamento, determinando descontinuidade e ineficiência. Este texto propõe o uso de técnicas indutivas, ao invés da coerção, como ferramenta para reconciliar planejamento e orçamento na Administração Pública. Como ferramenta indutiva, o texto apresenta a deferência às escolhas precedidas de planejamento $e$ orçamento. A deferência é traduzida numa prática com três estágios, a ser implementada pelos controladores: 1) conhecer as escolhas públicas, seus componentes e relações matriciais; 2) verificação de que a ação está se desenvolvendo de acordo com o planejado; e 3) crítica direcionada especificamente aos dados e argumentos de justificação da Administração. Adequação das escolhas públicas, identificada pela aplicação do critério da deferência, pode incentivar a adesão ao reclamo constitucional de políticas públicas suportadas por planejamento e orçamento.

Palavras-chave: planejamento; orçamento; políticas públicas; deferência; controle público.

\section{Abstract}

Constitutional clauses requires that planning and budgetary provisions should precede public choices. Despite that, public policy in Brazil is seldom properly translate into budget, leading to discontinuity and inefficiency. This paper proposes the usage of induction, instead to coercion as a tool to reconcile budgeting and planning in Public Administration. As an inductive tool, this paper presents deference into public choices preceded by planning and budgeting. Deference in translate into a tree steps practice to be implemented by controllers: 1) awareness of public choices, its components and matrix relations; 2) verification that acting is in accordance with planning; and 3) criticism addressing specifically Public Administration data and justification arguments. Adequacy of public choices, identified by application of the deference criteria can incentive adhesion to the constitutional requirement of a planned and budget supplied public policy.

Key-words: planning; budgeting; public policy; deference; public control.

\footnotetext{
Como citar esse artigo/How to cite this article: VALLE, Vanice Lírio do. Planejamento orçamentário e políticas públicas: explorando uma alternativa de reconciliação pela indução. Revista de Investigações Constitucionais, Curitiba, vol. 5, n. 2, p. 113-134, mai./ ago. 2018. DOI: 10.5380/rinc.v5i2.55250.

* Professora Permanente do PPGD da Universidade Estácio de Sá - UNESA (Rio de Janeiro-RJ, Brasil). Doutorado em Direito pela Universidade Gama Filho (Rio de Janeiro, Brasil). Visiting Fellow junto ao Human Rights Program da Harvard Law School (USA). Pós-doutorado em Administração pela EBAPE - Escola Brasileira de Administração Pública e de Empresas (FGV/Rio). Membro do Instituto Brasileiro de Direito Processual e Procuradora do Município do Rio de Janeiro. E-mail: vanicevalle@gmail.com.
} 


\section{SUMÁRIO}

1. Introdução; 2. Dissociação entre planejamento orçamentário e políticas públicas; 2.1 Elementos normativos e culturais a favorecerem a dissociação; $\mathbf{2} . \mathbf{2}$ Novos influxos no cenário da segmentação entre políticas públicas e sua projeção orçamentária; 3. Uma primeira opção estratégica: indução, mais do que coerção; 4. Construindo um acordo semântico: o que se entenda por deferência e seus efeitos; 4.1 O sentido tradicional da deferência como padrão de conduta no exercício do controle da Administração; 4.2 Deferência como signo orientador do processo de deliberação no exercício do controle da Administração Pública; 5. Indução pelo viés pragmático: como atrair o gestor público à lógica do planejamento que engloba a expressão orçamentário; 6. Referências.

\section{INTRODUÇÃO}

Aberto o campo do controle substantivo das políticas públicas inclusive em sede judicial, apresenta-se mais intensamente o problema da translação dos programas de ação para o orçamento por seus formuladores ou mesmo dos efeitos sobre essa mesma dimensão financeira da decisão fiscalizadora.

Inobstante a intuitiva relação entre políticas públicas e planejamento orçamentário, e a clara sinalização constitucional nesse mesmo sentido, seja pela alusão à eficiência na moldura principiológica posta à Administração, seja pelo contido no art. 167 CF; fato é que não se tem no agir dos entes públicos a interdependência lógica entre estes dois componentes que seria de se desejar. O rompimento dessa reciprocidade usualmente deitará graves efeitos no tema da continuidade da ação pública.

O objeto do presente texto é o apontamento de possíveis razões que conduzem a essa dissociação entre planejamento orçamentário e políticas públicas; tudo com o intuito de explorar a alternativa da adoção do critério de deferência para com as escoIhas administrativas empreendidas e executadas sob o signo do prévio planejamento e repercussão orçamentária como mecanismo indutor desse desejável alinhamento. A hipótese é de que a adoção do critério de deferência como orientador do controle externo induza a reconciliação entre os dois componentes, favorecendo à eficiência e materialização dos resultados desejados pela Constituição.

O texto se desenvolverá em 5 partes, a primeira delas se dedicando às questões de ordem metodológica. Na parte 2, empreende-se ao mapeamento de causas da segmentação verificada entre planejamento orçamentário e políticas públicas, num esforço de localizar quais sejam os elementos factuais que estejam contribuindo para a erosão de uma simbiose que a rigor, deveria defluir diretamente da literalidade da Constituição. A parte 3 expõe as razões pelas quais as ferramentas de indução - e não as de coerção - possam se revelar mais efetivas na reconciliação entre planejamento de ação e sua expressão financeira. A proposição se alinha com uma investigação que aposta na potencialização das capacidades institucionais, criando um ambiente que valoriza o resultado da ação de cada qual dos poderes. 
A deferência é objeto de cogitação específica na parte 4, onde se explora alguns dos seus sentidos mais tradicionais, para enfim propor uma compreensão que torna essa mesma aproximação um parâmetro para a objetivação do exercício do controle sobre a Administração Pública. Finalmente, na parte 5 tem-se a demonstração das razões que permitem afirmar possa a aplicação da deferência funcionar como mecanismo indutor à reaproximação entre planejamento e orçamento.

O texto se desenvolve a partir do método crítico dialético, fundado em pesquisa bibliográfica. A proposição que se apresenta tem por objetivo auxiliar no aperfeiçoamento dos mecanismos de controle da ação pública, seja a partir da perspectiva de seu desenho e implementação, seja no viés do exercício do controle objetivo do poder.

\section{DISSOCIAÇÃO ENTRE PLANEJAMENTO ORÇAMENTÁRIO E PO- LÍTICAS PÚBLICAS}

Não consiste novidade a afirmação de que se tenha consolidado no Brasil, uma dissociação entre planejamento orçamentário e políticas públicas. ${ }^{1}$ Manifestação mais clara dessa segmentação se tem nas incontáveis notícias originárias de autoridades executivas e de agentes do controle em relação a descontinuidades em ações públicas, frequentemente creditadas a dificuldades de ordem orçamentária - ausência ou insuficiência de previsão de recursos específicos; frustração ou desvios na execução desse mesmo orçamento quando existente a provisão. Ponto de partida para a superação dessa patologia é a diagnose das causas que determinaram esse apartamento.

\subsection{Elementos normativos e culturais a favorecerem a dissociação}

Se é verdade que o comando constitucional de eficiência já determinava a necessária qualificação da ação pública pelo signo do planejamento²; não é menos certo que outros elementos desse mesmo contexto normativo colidem com esse alinhamento. Primeiro deles é o ciclo alcançado pelo instrumento de perfil temporal mais alongado da tríade orçamentária, a saber, o plano plurianual (quatro anos). É certo que o art. $165, \S 9 \circ$, I CF remetia à lei complementar a disciplina da vigência do plano plurianual, permitindo em tese alongar esse interstício, compatibilizando-o com as iniciativas mais

\footnotetext{
1 Em alguma medida, esse distanciamento reflete uma dissociação identificada igualmente na literatura de políticas públicas, segunda a qual o planejamento (ou formulação) se tenha muitas vezes por segregado das condições de implementação; o primeiro de caráter eminentemente técnico, e o segundo orientado a problemas de cariz operacional (PUPPIM DE OLIVERIA, José Antonio. Desafios do planejamento em políticas públicas: diferentes visões e práticas. Revista de Administração Pública-RAP, Rio de Janeiro, vol. 40, n. 2. p. 273-288, mar./abr. 2006.). Se disponibilidade dos recursos orçamentários e financeiros se apresenta como condição sine qua non da implementação das políticas públicas traçadas, tem-se aqui o ponto comum na compreensão do indesejável afastamento entre as duas dimensões sob estudo.

2 BATISTA JÚNIOR, Onofre Alves. O princípio constitucional da eficiência administrativa. 2. ed. Belo Horizonte: Fórum, 2012. p. 225.
} 
longevas da Administração Pública. Essa matéria não se revelou capaz de incentivar a deliberação legislativa, sem que se tenha até hoje editada a referida lei complementar.

Registre-se ainda que embora seja real o descompasso originário do plano normativo, fato é que ele não se revela por si só suficiente para justificar a referida partição entre o processo de desenho das políticas públicas e a sua tradução no plano do direito financeiro. Mais ainda, essa separação se verifica mesmo no campo das ações públicas de curto prazo, o que convida à busca de outras alternativas justificadoras.

Um dos vieses explicativos envolve, em alguma medida, razões históricas. Como se sabe, a década de 70 associou ao ideário de planejamento e planificação (especialmente no campo econômico) uma carga semântica negativa, identificada com tendências ideológicas centralizadoras e autoritárias. ${ }^{3}$ Assim, não obstante o prestígio ao ideal de planejamento traduzido no Decreto-Lei $200 / 87^{4}$; fato é que esse traço não se disseminou pelas organizações públicas, que seguem ainda hoje, mais reativas do que programadas nas suas linhas de ação.

Outro elemento relevante é a falta de cultura de planejamento, perversamente alimentada no último quartil do século $X X$, pelo processo inflacionário sempre presente, e que tornava os mecanismos de orçamentários mais simbólicos do que reais. De outro lado tem-se um traço característico da sociedade brasileira, afeita a uma perspectiva mais imediatista das coisas, o que leva à secundarização do olhar prospectivo. Não se pode negar a cultura de valorização do improviso, como se a capacidade de ofertar alternativas sob o calor do momento fosse um atributo importante do brasileiro, apto a socorre-lo em quaisquer situações - ainda que isso se dê no plano da gestão da coisa pública.

Interfere igualmente na segmentação sob estudo, o próprio desenho institucional de operação da Administração Pública. Isso porque a lógica de prestígio à especialização funcional reclama a descentralização da atividade fim; mas no campo da atividade financeira, tem-se a centralização, não só na montagem em si dos instrumentos de planejamento orçamentário, mas também (se não principalmente) na sua execução. Evidente que macro decisões de gestão financeira pressupõe uma visão do todo em relação a elementos como qual o real comportamento da receita estimada, qual a capacidade de gasto de cada qual dos múltiplos atores desse mesmo processo, etc. Esse reclamo pode justificar a opção pela centralização da gestão financeira. De outro lado, as decisões relacionadas às prioridades e intensidade da ação pública a ser desenvolvida, são urdidas pelos órgãos técnicos, e, portanto, tendem à segmentação. Convivendo

\footnotetext{
3 MINDLIN, Betty. Introdução - o conceito de planejamento. In: (Org.). Planejamento no Brasil. 6. ed. São Paulo: Perspectiva, 2010. p. 9-28.

4 Em verdade, o planejamento constitui o princípio dominante da reforma administrativa empreendida pelo Decreto-Lei 200/67 (WAHRLICH, Beatriz. A reforma administrativa no Brasil: experiência anterior, situação atual e perspectivas: uma apreciação geral. Revista de Administração Pública - RAP, Rio de Janeiro, vol. 18, n. 1. p. 49-59, 1984. p. 52).
} 
estímulos à centralização e à descentralização, o resultado no campo da gestão financeira é a perda da sinergia entre essas duas visões, com a prevalência usual, dada a permanente escassez de recursos, do critério do órgão central de gestão financeira. ${ }^{5}$

Terceiro elemento que contribui para o desmembramento entre planejamento e políticas públicas é a competição estabelecida entre os interessados (agentes públicos executores de políticas públicas), uma vez mais, seja na elaboração do planejamento orçamentário, seja na sua execução. Nessa disputa de recursos escassos, muitas vezes vencerá quem tenha maior prestígio pessoal, ou responda por área de atuação que diga mais de perto às prioridades políticas daquela específica gestão. Efeito ainda perverso será a circunstância de que nesta contenda, a linguagem que se apresentará como comum a todos os participantes é aquela do dinheiro; de quanto de gasto público se tem em discussão. Os critérios de decisão do órgão central de planejamento orçamentário gravitam igualmente nesse campo: quais são as aplicações obrigatórias? Qual a capacidade de gasto de cada qual dos stakeholders em contenda? Com isso, tem-se secundarizado o debate quanto às políticas públicas que possam vir a sofrer efeitos deletérios com o contingenciamento ou remanejamento de recursos em disputa. Confiam-se os recursos àquelas iniciativas que tem a si associadas dispêndios obrigatórios, ou àquele que tem real capacidade de gasto - ainda que não se tenha nesse campo o desenvolvimento pleno de uma política pública revestida de especial prioridade, ou cuja interrupção ou reconfiguração por problemas de financiamento gere efeitos sociais graves.

Quarto elemento no cenário do afastamento entre planejamento orçamentário e políticas públicas, é a aversão dos agentes políticos aos efeitos vinculantes da ação planejada. Num cenário de incertezas econômicas, políticas ou sociais, o gestor por vezes não deseja se comprometer com a enunciação de programas detalhados, eis que sua enunciação constringe sua conduta posterior, que se espera coerente com esse mesmo plano de ação. Isso tem ainda por reflexo a diminuição da margem de negociação política do administrador, que terá mais dificuldades em descontinuar um curso de ação claramente definido para acomodar demandas políticas supervenientes. A par disso, a ação planejada exige um esforço maior de argumentação e construção racional; ela refoge do conforto da decisão automática ditada por regras de experiência, e incrementa o ônus de justificação da escolha pública. ${ }^{6}$

\footnotetext{
5 Esse tema já foi apontado em trabalho anterior que aludia ao problema do uso de recursos comuns - onde se percebe os recursos a partir de uma visão do todo, e os gastos a partir da perspectiva de parte, o que leva sempre à impressão, de parte de quem disputa por verbas, de que os recursos existem (no todo); eles só não estão a seu alcance (na parte). (VALLE, Vanice Regina Lírio do. Função administrativa e orçamento: o espaço negligenciado de efetividade dos direitos fundamentais. In: GUERRA, Sérgio; FERREIRA JR., Celso Rodrigues (Orgs.). Direito Administrativo. Estudos em homenagem ao Professor Marcos Juruena Villela Souto. Belo Horizonte: Fórum, 2015. p. 398-418).

6 Para uma ampla exposição acerca da preferência humana acerca da deliberação orientada pelo chamado "modo automático", influenciado predominantemente por expedientes lógicos construídos a partir de experiências pretéritas, reprodução de práticas sociais generalizadas e outros mecanismos - tudo em oposição do
} 
No campo específico da execução orçamentária, é de se sublinhar outros traços limitadores de nosso sistema constitucional no que toca à integração em si das atividades de planejamento e sua dimensão financeira. A lógica de nossa constituição é de que o administrador formule as políticas públicas que pretende pôr em curso; isso se traduza em estimativa de despesas refletida no orçamento que é depois executado. É certo que há intempéries que se põe ao longo da execução: a estimativa de receita pode se revelar equivocada, e, portanto, não se tem cobertura financeira para o conjunto de despesas planejadas; é possível que surja uma necessidade específica não prevista decorrente de desastres naturais ou outros fenômenos; um conjunto de fatores podem se apresentar que exijam alguma reconfiguração do planejamento. Destaque-se que essas contingências são normais, e não expressam em si qualquer vício na formulação do desenho original de ação. Cenários de instabilidade política e econômica aumentam a probabilidade da recalibragem orçamentária ao longo do exercício.

Fato é que sobrevindo a intercorrência e imponível a reconfiguração da expressão financeira do planejamento, os mecanismos ofertados pelo texto constitucional são rígidos, e não se mostram desprovidos de custo político. A abertura de créditos especiais tem o custo político de nova submissão ao legislativo, e tem ainda o custo -oportunidade, eis que a decisão parlamentar nem sempre acontece com a velocidade que se deseja. A par disso, a reconfiguração de que se cogita acontece ao longo da execução, e não dispõe do tempo necessário para que se estabelecesse uma ampla discussão em torno de qual política pública deverá ser destinatária de cortes, ou mesmo de paralisação. O tempo aqui corre contra a decisão mais refletida, e as soluções muitas vezes são arbitrárias - ou a redução uniforme de " $x$ ", sem qualquer avaliação da repercussão desse corte linear nos programas de ação em curso; ou a simples descontinuidade desse ou daquele programa.

A diagnose, portanto, até agora, é de que temos uma dupla segmentação: 1) fratura entre o planejamento inicial da política pública e a sua tradução nos instrumentos de programação financeira; e 2) dissociação entre o planejamento orçamentário e a sua execução, que pode ser colhida por intercorrências que redefinam opções iniciais. Ambos os efeitos são nocivos. Uma política pública, ainda que formulada em padrão de excelência, se não for refletida inicialmente no orçamento, resultará em inexecução total, ou execução em condições precárias, com inevitável comprometimento do resultado. De outro lado, reconfigurações da execução orçamentária podem ser definidas de maneira aleatória, afetando componentes centrais de uma ação pública sem que esse efeito deletério tenha sequer sido considerado.

chamado modo reflexivo de decisão - consulte-se THALER. Richard H.; SUNSTEIN, Cass. Nudge: Improving decisions about health, wealth and happiness. New Haven \& London: Yale University Press, 2008. p. 293. 


\subsection{Novos influxos no cenário da segmentação entre políticas públicas e sua projeção orçamentária}

Primeira mudança no quadro é a instituição do novo regime fiscal, trazido ao plano federal por força da Emenda 95, e em vias de se espraiar no plano estadual, ao menos em relação àqueles entes federados que se venham a aderir ao chamado Regime de Recuperação Fiscal estatuído pela Lei Complementar 159/17. Essa inovação traz como consequência imediata a consolidação da lógica de que o primeiro passo no desenho da ação pública passa a ser a delimitação dos recursos (em tese) disponíveis, e a partir disso dá-se a construção do planejamento. Isso não é em si um mal, mas define sentido específico à relação entre planejamento e orçamento.

Outra circunstância que se reflete nesse mesmo quadro de dissociação entre planejamento orçamentário e políticas públicas é a ampliação do tempo da ação estatal sem correspondência no perfil temporal desses mesmos instrumentos. Esse fenômeno, particularmente manifesto no segmento da infraestrutura, revela-se preocupante pelo que pode determinar de instabilidade das relações contratuais estabelecidas pela Administração. Afinal, esses elementos de incerteza que entram no cenário do agente privado que contrata com a Administração vão ter o seu impacto na precificação.

Ainda no conjunto de novos vetores trazidos ao problema em debate, tem-se a ampliação da lógica da construção por iniciativa da União, de "sistemas" relacionados à efetivação de direitos fundamentais, com a consequente criação de deveres de agir unilateralmente direcionados a todos os entes federados integrantes desta mesma estrutura. A expressão "sistema" vem sendo utilizada indistintamente, seja para aludir a uma base de dados informacional, seja para identificar um conjunto de ações públicas cometidas a diversos entes federados, coordenadas por um ente central - normalmente a União. A opção estratégia de constituição desses "sistemas" tem se materializado seja com a edição de emenda constitucional ${ }^{7}$, seja por normatividade infraconstitucional ${ }^{8}$, e já se tem por presente em diversas áreas, tematizando inclusive qual seja o regime de responsabilidade dos entes federados que se articulam, especialmente no regime de cooperação do art. 23 da CF. ${ }^{9}$ Embora o discurso de justificação seja a construção de ações articuladas, como manifestação inclusive do federalismo de cooperação, fato

\footnotetext{
7 Essa foi a opção adotada no âmbito da cultura, com a edição da Emenda Constitucional 71/12, que no tema específico, acrescentou o art. 216-A que inaugura o chamado Sistema Nacional de Cultura.

8 A título de mera ilustração desta tendência, indica-se a Lei 12.305 de 12 de agosto de 2010, que instituindo a Política Nacional de Resíduos Sólidos alude a vários "sistemas"; e ainda a Lei 12.608 de 10 de abril de 2012, que outras providências, cria o Sistema Nacional de Proteção e Defesa Civil.

9 É de Bercovici a explicitação de que no regime de cooperação preconizado pelo art. 23 CF, tem-se a exigência de ação conjunta de todos os entes federados, que devem colaborar para a execução das tarefas determinadas pela Constituição (BERCOVICl, Gilberto; SIQUEIRA NETO, José Francisco. O artigo 23 da Constituição de 1988 e as competências comuns. Revista brasileira de estudos constitucionais - RBEC, Belo Horizonte, Ano 2, nº 6. p. 49-65, abr./jun. 2008).
} 
é que tais sistemas muitas das vezes põem integrantes do "sistema", deveres de agir que não se tinha antes formalmente assentados, e que podem não guardar perfeita sintonia com as políticas públicas em curso em cada qual dos entes federados que são compulsoriamente incluídos. Dá-se aqui portanto, mais uma fratura entre o planejamento orçamentário e as políticas públicas em curso, agora não por fatores internos à organização, mas pela intervenção centralizadora da União.

Último elemento a compor o quadro de análise do tema proposto, é a curva crescente de controle judicial da Administração e os seus efeitos, seja no desenho das políticas públicas, seja do planejamento orçamentário. Como se sabe, resta assentado pelo Supremo Tribunal Federal a ideia de que é possível - ainda que em caráter excepcional - o controle judicial de políticas públicas ${ }^{10}$, especialmente em hipóteses onde se tenha por inexistente ou claramente ineficaz as ações públicas em curso. Se em momento primeiro dessa abertura ao controle judicial das políticas públicas, a eventual repercussão em sede orçamentária se revelava como um elemento de contenção da Corte; fato é que a vulgarização do argumento da reserva do possível culminou por levar o Judiciário a afirmar que o manejo dessa cláusula de bloqueio não poderia se dar sem a adequada demonstração de que os recursos efetivamente não existem, e não podem ser remanejados sem grave prejuízo a outras atividades. ${ }^{11}$

Cumpre destacar a especial relevância desse último componente - a possível intervenção judicial controladora de políticas públicas com repercussão no orçamento - no tema sob análise. Isso porque, primeiramente, a decisão judicial tende a ser de caráter pontual, e, portanto, aprecia os eventuais efeitos práticos sob as finanças públicas a partir de uma visão segmentada, desconsiderando um provável efeito multiplicador. De vez que os recursos são inequivocamente limitados (quando menos pela previsão de receita), a criação de nova despesa por ordem judicial implica na constrição ou cessação de alguma outra ação pública, que não é considerada quando da sentença. Aqui, tem-se o paradoxo da centralização/descentralização já antes analisado sob a perspectiva interna da Administração levado ao seu extremo - as decisões judiciais condenatórias são descentralizadas, e o cumprimento é centralizado.

\footnotetext{
10 Para um percurso da evolução do tema na jurisprudência do Supremo Tribunal Federal e do Superior Tribunal de Justiça, consulte-se VALLE, Vanice Regina Lírio do. Direitos fundamentais, políticas públicas e controle judicial. 2. ed. Belo Horizonte: Fórum, 2016.

11 Essa compreensão se teve por sintetizada na tese de repercussão geral adotada no julgamento do RE 592.581, assim enunciada: É lícito ao Judiciário impor à Administração Pública obrigação de fazer, consistente na promoção de medidas ou na execução de obras emergenciais em estabelecimentos prisionais para dar efetividade ao postulado da dignidade da pessoa humana e assegurar aos detentos o respeito à sua integridade física e moral, nos termos do que preceitua o art. 5०, XLIX, da Constituição Federal, não sendo oponível à decisão o argumento da reserva do possível nem o princípio da separação dos poderes. (BRASIL, Supremo Tribunal Federal. RE 592581, Relator(a): Min. RICARDO LEWANDOWSKI, Tribunal Pleno, julgado em 13/08/2015, ACÓRDÃO ELETRÔNICO REPERCUSSÃO GERAL - MÉRITO DJe-018 DIVULG 29-01-2016 PUBLIC 01-02-2016).
} 
A par disso, não se pode desconsiderar que a judicialização do tema do orçamento e dos gastos públicos, seja por intermédio de demandas individuais ou coletivas, seja pela via do controle abstrato, pode permitir a captura do debate. Ilustra essa afirmação, dentre outras, a ADI 5633 ${ }^{12}$, que tem por objeto a Emenda Constitucional 95, instituidora do chamado Novo Regime Fiscal, impugnada pelas Associação dos Juízes Federais do Brasil, Associação Nacional dos Magistrados da Justiça do Trabalho, Associação dos Magistrados Brasileiros - todas suscitando a suposta vulneração às garantias institucionais do Poder Judiciário dela decorrentes e a consequente inaplicabilidade ao Judiciário desses mesmos limites. É certo que em debate desse jaez, a decisão trará como consequência inafastável, um trade off que acontecerá para a viabilização das medidas de ajuste, sendo previsível a redução dos gastos públicos tidos como incompressíveis, a saber, custeio e programas sociais. Esse efeito não se tem por discutido no curso do processo. ${ }^{13}$

Esse quadro de complexidade evidencia a urgência em se resgatar a importância da sintonia entre planejamento orçamentário e políticas públicas, seja para fins de incrementar a probabilidade de efetiva concretização das ações delineadas, seja para evitar efeitos deletérios de se ter como aceitável essa segmentação. Mas como avançar nesse propósito?

\section{UMA PRIMEIRA OPÇÃO ESTRATÉGICA: INDUÇÃO, MAIS DO QUE COERÇÃO}

O exercício exploratório de alternativas de enfrentamento da noticiada dissociação entre ação pública e o dever de planejamento (especialmente o orçamentário), se propõe seja exercido com ênfase nos mecanismos de indução - ao revés do caminho aparentemente mais fácil da coerção. Isso se propõe por várias razões.

Primeiro, no campo repressivo, os mecanismos já existem, com distintas arquiteturas normativas e com baixo índice de resolutividade. A Lei 8429/92 (Lei de Improbidade Administrativa) optou, por exemplo, pela incorporação de uma tipificação aberta, em especial na cláusula contida em seu art. 11, o que se supunha ampliaria o espectro de condutas alcançáveis pela qualificação de improbidade, otimizando o potencial de coibição de desvios de conduta administrativa. ${ }^{14}$ No tema em discussão, parece claro

12 BRASIL. Supremo Tribunal Federal. ADI 5633, Relatora a Min. Rosa Weber - ainda em processamento, sem decisão proferida.

13 VALLE, Vanice Regina Lírio do. Novo Regime Fiscal, autonomia financeira e separação de poderes: uma leitura em favor de sua constitucionalidade. Revista de Investigações Constitucionais, Curitiba, vol. 4, n. 1, p. 227-258, jan./abr. 2017.

14 O uso generalizado de cláusulas abertas na legislação orientada ao exercício do controle é sublinhados por Marques e Palma, destacando ainda o quanto isso implica em aumento do grau de subjetividade do controlador (MARQUES NETO, Floriano de Azevedo; DE PALMA, Juliana Bonacorsi. Os sete impasses do controle da 
que a dissociação entre planejamento orçamentário e políticas públicas é prática que entra em linha de contraste, pelo menos, com o princípio da eficiência - o que poderia em tese atrair o enquadramento da conduta como improbidade. Não há notícia, todavia, de que a repressão a essa prática nefasta do agir voluntarista e reativo do gestor se dê nessa via, e menos ainda, com êxito.

A Lei Complementar 101/00 (Lei de Responsabilidade Fiscal) optou por outra estratégia, com a indicação expressa de elementos formais relacionados à elaboração e execução orçamentária que haveriam de ser atendidos ${ }^{15}$, elementos esses que em tese reforçam a simbiose entre planejamento orçamentário e políticas públicas. Também por essa via não se parece ter avançado muito no resgate da desejada sintonia.

Nem sempre o instrumento de coerção será aquele mais adequado para obter o aprimoramento desejado na ação estratégica do administrador. Afinal, as estratégias orientadas à coerção oportunizam de outro lado, intenso debate quanto à exigibilidade do elemento subjetivo da conduta, e da estrita observância das garantias de ampla defesa, o que culmina por enfraquecer o exercício do controle. E porque o instrumento de indução pode se revelar mais acertado para o resultado que aqui se busca? Porque o bom planejamento, aquele que enfrenta as situações de complexidade e diversidade que vivemos hoje exige um ânimo de investigação, de exploração de alternativas, de inovação - e o ambiente da repressão não favorece isso. Não há como estimular pela via da coerção, o desenvolvimento de soluções criativas, que otimizem os recursos existentes e criem a desejável sinergia entre as estruturas administrativas. A contrário, a ênfase nesse viés coercitivo levará a um planejamento formulado puramente para atendimento ao requisito formal - sem compromisso maior com o desejável esforço de inovação, ou mesmo com a sua execução. ${ }^{16}$

Para que o planejamento se incorpore efetivamente à ação da Administração Pública, não obstante todos os obstáculos referidos no item 2 acima, é preciso que se

administração pública no Brasil. In: PEREZ, Marcos Augusto; SOUZA, Rodrigo Pagani de. Controle da administração pública. Belo Horizonte: Forum, 2017. p. 21-38.)

15 O detalhamento dos anexos de metas e riscos, desenhado pelo art. $4^{\circ}$ da Lei Complementar 101/00 investe no fortalecimento do cenário prospectivo, reverente ao viés de prudência preconizado na definição empreendida pelo mesmo instrumento legislativo em seu art. 10, Parágrafo Único, do que seja gestão fiscal responsável. Na mesma linha, a exigência contida no art. 16 da Lei de Responsabilidade Fiscal de que aumento de despesa se revista de adequação para com a lei orçamentária anual e os demais instrumentos da tríade orçamentária robustece o dever de harmonização entre ação pública e planejamento.

16 O bloqueio à inventiva do administrador e o predomínio das fórmulas já testadas é apontado por Mascarenhas como decorrência de uma cultura do medo, instaurada pela ameaça permanente de uma ação de controle descomprometida com a prévia compreensão do quadro fático e de constrições que efetivamente se ponha à ação do gestor público (MASCARENHAS, Rodrigo Tostes de Alencar. O medo e o ato administrativo. Revista Direito do Estado. no 289, Ano 2016. Disponível em: <http://www.direitodoestado.com.br/colunistas/ rodrigo-tostes-mascarenhas/o-medo-e-o-ato-administrativo >. Acesso em: 01 set. 2017.). 
Ihe reconheça valor jurídico substantivo ${ }^{17}$, especialmente quando se sindica a juridicidade de sua conduta no âmbito da ação de controle. É necessário que a sua realização confira à ação precedida de planejamento, efeitos jurídicos perceptíveis, distintos daqueles conferidos à ação meramente reativa, e que transformem esse modelo de atuação naquele preferencial ao gestor público.

Investir no caminho da indução ao planejamento envolve recepcionar a ideia de que realidades não experimentads reclamam valores novos. Assim, num universo de crescente complexidade como aquele em que opera a Administração Pública, a diversidade de estratégias, o experimentalismo, o abdicar da lógica de uma única solução possível são elementos que hão de ser abarcados como admissíveis - desde que num contexto de ação planejada, a revelar tenha sido fruto de deliberação racional e de ponderação de riscos. O estímulo ao agir programado tende ainda a reforçar a continuidade nos programas de ação como um valor a ser protegido, desde que arrimada na avaliação e beneficiada pelo aprendizado por agregação proporcionado exatamente por este continuum.

Cabe assinalar que a ênfase na coerção como meio de enforcement pela Administração Pública de suas próprias determinações já não se põe em suas relações para com a sociedade como única alternativa. O uso da consensualidade como estratégia na construção de acordos com vistas à satisfação de interesses públicos tem-se hoje por internalizado no Direito Administrativo: "a face imperativa do Poder só deve aparecer quando absolutamente necessário e no que for absolutamente indispensável". ${ }^{18} \mathrm{~A}$ par da necessária atuação do Estado no campo do fomento, tem-se ainda a referência a uma função sua de incitação; um Estado que renuncia à coerção para exercer uma influência sobre os comportamentos, uma "pilotagem indireta", que apoia a auto-organização da sociedade. ${ }^{19}$

A pergunta que se põe é: se a Administração Pública pode valer-se de técnicas de incitação nas suas relações externas, com a cidadania e os usuários de seus serviços; porque não aplicar essa mesma perspectiva quando se cuida, no âmbito do controle, do delineamento dos atributos exigíveis de sua ação?

\footnotetext{
17 O tema foi desenvolvido por Sundfeld, como pressuposto para incorporação da inovação na ação da Administração Pública na palestra "Inovações em Direito Público" no Congresso de mesmo nome, havido na Procuradoria Geral do Estado do Rio de Janeiro (SUNDFELD, Carlos Ari. Inovações em Direito Público, disponível em < https://www.youtube.com/watch?v=pttTPjiNbtw\&t=521s >. Acesso em: 18 ago. 2017).

18 MOREIRA NETO, Diogo de Figueiredo. Novas mutações juspolíticas. Em memória de Eduardo García de Enterría, jurista de dois mundos. Belo Horizonte: Fórum, 2016. p. 177.

19 MORAND, Charles Albert. Le droit néo-moderne des politiques publiques, Paris: Librarie Génerale de droit et de jurisprudence, 1999. p. 159.
} 
Não se está com isso recuando na afirmação de que exista um dever de planejamento ${ }^{20}$, nem se deseja esvaziar de conteúdo essa mesma cláusula. A proposta, ao contrário, é associar à ação planejada e executada conforme esse mesmo planejamento, uma valoração adicional, com efeitos jurídicos substantivos. Esse signo adicional se traduziria na aplicação, no âmbito do controle, do critério da deferência - conduta que como exposto abaixo, se crê tenha relevante potencial indutor da reconciliação entre ação administrativa e seu dever de planejamento, com a indispensável tradução na dimensão das finanças públicas.

\section{CONSTRUINDO UM ACORDO SEMÂNTICO: O QUE SE ENTENDA POR DEFERÊNCIA E SEUS EFEITOS}

Da vedação à sindicabilidade as escolhas discricionárias à admissibilidade do controle irrestrito destas mesmas opções, tem-se um vasto leque de soluções intermediárias, inclusive aquelas que preconizam o uso da deferência como critério limitador do espectro de controle. O sentido que aqui se oferece a essa mesma expressão (deferência) apresente contornos distintos daquele presente na literatura mais frequente, que merecem ser aclarados.

\subsection{O sentido tradicional da deferência como padrão de conduta no exercício do controle da Administração}

O termo "deferência", no seu sentido comum, relaciona-se a uma atitude de respeito e consideração, frequentemente associada a uma assimetria entre aquele que é deferente, e o merecedor da deferência. Há outro sentido igualmente ofertado à palavra ainda na linguagem coloquial, que mais se aproxima daquilo de que aqui se cogita, a saber: interesse pelos assuntos alheios, atenção para com o ponto de vista do outro.

Na interseção entre Administração Pública e o Judiciário como agente de controle externo, tem-se a utilização do termo deferência para expressar aproximação por estes últimos em relação à ação pública controlada: "adoção pelos tribunais de uma postura auto-restritiva no controle que operam sobre as decisões administrativas".21 Observe-se que a inclinação auto-restritiva não impede o exercício do controle, mas constringe aquilo que seja objeto de consideração. Neste sentido, tem-se na adoção da deferência, um ponto de partida para a delimitação do âmbito de escrutínio da ação

\footnotetext{
20 Em verdade, a afirmação de um dever constitucional de planejamento, traduzido na formulação de políticas públicas, é tema que já foi objeto de consideração anterior em VALLE, Vanice Regina Lírio do. Dever constitucional de enunciação de políticas públicas e autovinculação: caminhos possíveis de controle jurisdicional. Fórum Administrativo, Belo Horizonte, v. 82. p. 7-19, 2007.

21 JORDÃO, Eduardo. Controle judicial de uma Administração Pública complexa: a experiência estrangeira na adaptação da intensidade do controle. São Paulo: Malheiros Editores, 2016. p. 50.
} 
administrativa, com reflexos inclusive no ônus argumentativo exigível para fins de reprovação dessa mesma conduta.

O tema da deferência como conduta possível (ou exigível) de parte do Judiciário no controle da Administração Pública tem intensa aplicação igualmente no cenário estadunidense. No ainda hoje discutido caso Chevron U.S.A. Inc. v. Natural Resources Defense Council, Inc. ${ }^{22}$, a Suprema Corte afirmou que em hipóteses onde não tenha o legislador disposto especificamente sobre determinado tema, ou em cláusulas legais onde se possa verificar ambiguidades, o crivo judicial é de se dar a partir de uma perspectiva de deferência para com a escolha regulatória. ${ }^{23}$ Independente das especificidades do debate norte-americano, útil é a enunciação empreendida por Scalia do conceito de deferência: prática que importa em reconhecer como valor constitucional a consideração do ponto de vista externado pela Administração com atenção e respeito, antes de proceder-se à sua rejeição. ${ }^{24}$

Em verdade, as duas conceituações até aqui declinadas guardam relação de complementariedade: o agente controlador (Judiciário, ou qualquer outra das estruturas de controle) restringe sua própria ação de escrutínio quanto à ação investigada, porque se reconhece valor constitucional à interpretação empreendida pela Administração Pública acerca dos seus deveres e possibilidades na matéria. ${ }^{25} \mathrm{O}$ fundamento para essa mesma conclusão pode repousar no argumento mais restritivo da delegation doctrine, ou ainda naquele debate mais amplo do respeito às capacidades institucionais próprias a cada uma das estruturas de poder a desenvolverem a função administrativa. ${ }^{26}$

Numa ou n'outra hipótese, a deferência estará a envolver um padrão de comportamento de parte do controlador fixado a partir da simples presença de uma estrutura administrativa revestida de capacidades institucionais próprias e que nessa condição, empreende à interpretação constitucional e formula escolhas quanto a seus programas de ação. Essa mesma inspiração se poderia encontrar, no sistema brasileiro, na presunção de legalidade e veracidade dos atos administrativos, decorrente também ela, de um critério de pertinência subjetiva - porque a ação é desenvolvida pela Administração Pública, e porque ela se rege pelos princípios constitucionais enunciados,

22 UNITED STATES. Supreme Court of the United States. Chevron U.S.A., Inc. v. Natural Resources Defense Council, Inc., 467 U.S. 837 (1984).

23 O tema dos limites da decisão Chevron, como se disse, são tremendamente controvertidos, havendo quem sustente âmbitos de incidência mais estreitos para a aplicação do critério de deferência.

24 SCALIA, Antonin. Judicial deference to administrative interpretations of law. Duke Law Journal, Durham, n. 3. p. 511-521, jun. 1989. p. 514.

25 O tema da relevância da interpretação constitucional (e por via de consequência, das escolhas públicas formuladas segundo essa mesma interpretação) é abordado de forma mais ampla em VALLE, Vanice Regina Lírio do. PULCINELLI, Eliana; MANEIRO, Renata de Marins Jaber (Coord). Contestação, persuasão e consenso no STF: construindo um constitucionalismo democrático. Rio de Janeiro: Gramma, 2016.

26 Nessa linha, o conhecido trabalho de SUNSTEIN, Cass; VERMEULE, Adrian. Interpretation and institutions. Michigan Law Review, Michigan, vol. 101, n. 4. p. 885-951, 2003. 
em especial, no art. 37, caput CF, tem-se a presunção. De outro lado, eis que relativa a praesumptio, seu efeito jurídico imediato será a inversão do ônus da prova - deixando aberto o espaço de debate em torno do que se tenha por suficiente para demonstrar a violação a qualquer dos princípios retores da Administração.

\subsection{Deferência como signo orientador do processo de deliberação no exercício do controle da Administração Pública}

O reclamo da deferência no sentido proposto neste texto não se põe como um prius de adequação da conduta da Administração, decorrente da sua simples pertinência subjetiva. O critério se propõe ampliar, para compreender um controle substantivo do processo de formação da escolha, pela simples circunstância de que a opção constitucional em subordinar finalisticamente o poder à concretização dos objetivos fundamentais da República e dos direitos fundamentais determina uma investigação quanto à observância dos critérios objetivos de legitimação do poder.

A deferência de que aqui se cogita, é estratégia procedimental aplicável ao exercício do controle por qualquer de suas estruturas, que direciona a análise da escolha administrativa ao prestígio àquela que foi precedida do devido processo de planejamento - da construção da política pública, até a sua projeção orçamentária. A lógica é de que o percurso do iter necessário à materialização do planejamento, nisso se incluindo sua tradução na dimensão orçamentária, permita a formação de um juízo de adequação da escolha pública que a um só tempo direcione o debate judicializado, e torne objetiva a discussão em torno do (des)valor da escolha pública.

Essa mesma técnica traduzir-se-á em três distintos estágios que hão de estar presentes no exercício do controle: $1^{\circ}$ ) conhecer a ação pública em curso e suas razões determinantes; $2^{\circ}$ ) avaliar se a ação pública em curso está se desenvolvendo segundo o desenho do planejamento; e $3^{\circ}$ ) promover ao diálogo entre as razões da Administração, e as objeções do agente controlador. A prática da deferência emancipa-se do critério do agente, que requer tão-somente a presença do sujeito Administração, para compreender o conjunto de vetores que orientaram e se traduziram na sua opção por determinados programas de ação, escolha essa que há de se revelar vocacionada a transpor o gap entre planejamento e dimensão financeira, reconciliando os dois vetores.

Conhecer a ação pública em curso (primeiro vetor exigível para a aplicação da deferência) envolve não só o conjunto material de atos que tenha determinado a eventual impugnação judicial, mas saber qual seja a sua inserção no planejamento maior da Administração. Importante conhecer suas relações de interconexão com outros programas públicos em curso (no âmbito da Administração controlada, ou mesmo em relação de coordenação ou cooperação com outros entes federados), bem como sua tradução nos instrumentos de direito financeiro. Tem-se já aqui uma substantiva modificação no 
modo de relação a se travar entre judiciário controlador, e Administração controlada. Afinal, no mais das vezes, estes elementos não se conterão em instrumentos normativos, e só podem ser alcançados em diálogo direto com os agentes públicos incumbidos da concretização da ação controlada. É possível igualmente que o "conhecer" a atividade sob crivo, nos termos da deferência que se está a propor, exija o desenvolvimento de uma linguagem comum, para que as peculiaridades da realidade sobre a qual incide a ação administrativa sob crivo sejam compreensíveis para o controlador. ${ }^{27}$

O segundo componente da deferência que se está propondo permitirá a aferição da aderência entre planejamento, orçamentação e prática. Isso porque o descompasso pode ser originário, conforme demonstrado no subitem 2; mas também pode ser superveniente, com o abandono pela Administração das estratégias que ela mesma propusera a si, ou ainda pela reconfiguração de seu agir ditada por constrições orçamentárias que bloqueiem o resultado originalmente cogitado.

Evidente que quando se tem em conta a avaliação da execução da ação pública, é de se recepcionar algum grau de flexibilidade à Administração executora, de vez que é no campo da implementação das políticas públicas que por vezes se identificam as erronias do planejamento e a necessidade de inovação. ${ }^{28}$ Excessivo rigor na aferição deste segundo atributo requerido para a outorga do signo da deferência (adesão ao planejamento) implicaria uma vez mais em retroalimentar a vagueza e indeterminação dos planos para evitar a imputação de desvio. A virtude residirá no meio-termo, com a incorporação de algum grau de flexibilidade em favor da Administração no plano da aplicação, maleabilidade essa que terá por contrapartida o dever de plena documentação das razões que levaram ao ajuste do plano original.

Presentes os dois atributos acima referidos, a deferência para com a escolha administrativa precedida de planejamento integral, com projeção na dimensão orçamentária, é de determinar uma presunção de adequação da escolha pública, que operaria em favor da continuidade da ação pública que já se tenha em curso.

Finalmente, o terceiro componente - crítica à ação controlada a partir de uma dialética com as razões da Administração declinadas no planejamento - permite uma reorientação da atividade do controle para o campo objetivo. O dissenso expresso por quem provoca seu exercício segue possível, mas a censura judicial da escolha administrativa passa a exigir um exercício racional acerca da inadequação da escolha do Estado, contraditando objetivamente suas razões, agora já conhecidas por exigência do primeiro componente proposto para a deferência. Sem dúvida, a presunção é juris

\footnotetext{
27 Abre-se aqui espaço para tornar o controlador um pensador prático do Direito Administrativo, identificado por Sundfeld como aquele "pensa em uma organização concreta, que conhece a partir das normas e da realidade" (SUNDFELD, Carlos Ari. Crítica à doutrina antiliberal e estatista de direito administrativo. In:

Direito administrativo para céticos. 2. ed. São Paulo: Malheiros. p. 113-144)
}

28 RATTNER, Henrique. Planejamento e bem-estar social. São Paulo: Perspectiva, 1979. p. 9. 
tantum, mas é de se operar efetivamente, revertendo-se a lógica cultural segundo a qual o Estado escolhe sempre mal, e age errado.

Este terceiro estágio da deferência resulta, a rigor, do signo de adequação, e pretende superar uma busca (utópica) da solução ótima, a partir de uma perspectiva puramente subjetiva do controlador. O que se investiga, portanto, não é o alinhamento da visão da Administração com aquele de quem Ihe controla; mas a aferição em concreto da adequação da escolha. Objetiva-se o controle do poder porque ele passa a ser exercido, não a partir de categorias abstratas manejadas puramente no plano da argumentação, mas sim a partir de uma escolha em concreto, que deu resposta a um cenário de problema definido, e que tem compromisso com o alcance de um resultado específico. A aplicação da deferência envolve não um debate acerca da superioridade da opção do controlador sobre aquela da Administração - porque esse debate, a rigor, pertence ao plano da política ou da discricionariedade. O que se cogita na presente proposta, é reconduzir o juízo crítico à ação pública planejada, a um exercício dialético com o cenário e os motivos indicados pelo gestor público, intensificando o ônus argumentativo de quem movimenta o controle, seja na demonstração das falhas da Administração, seja na apresentação de uma alternativa que ação que não traduza aqueles mesmos equívocos.

Importante ter em conta que uma das razões para o ceticismo em terra brasilis relação à deferência no modelo estadunidense, fundada no argumento das capacidades institucionais, repousa na circunstância de que por vezes essa superior aptidão institucional em abstrato não se revela presente na atuação da estrutura ou órgão público por distorções decorrentes da prática. ${ }^{29} \mathrm{O}$ sentido que aqui se propõe à deferência, de outro lado, corrobora a ideia de que a capacidade institucional originalmente concebida quando do desenho daquela estrutura se tem por efetivamente traduzido enquanto prática institucional - seja com o planejamento adequadamente desenvolvido até a sua transposição para a Lei de Meios; seja com a implementação desse mesmo programa de ação nos termos em que ele foi concebido.

A ampliação dessa lógica da capacidade institucional, do plano da sua proclamação em abstrato como premissa em favor do sujeito, para uma constatação em concreto, autoriza a já indicada presunção de adequação da escolha, o que incremente a chance de continuidade da ação estatal adequadamente planejada e executada. O resultado é maior estabilidade às linhas de ação planejada, intensificando as

29 Embora a referência se tenha dado em relação à percepção no cenário nacional, cumpre registrar que a desconfiança para com as escolhas administrativas e o debate em torno da amplitude do controle judicial se identifica igualmente em terras estadunidenses, onde se cunhou a categoria Estado Administrativo (SUNSTEIN, Cass; VERMEULE, Adrian. The Unbearable Rightness of "Auer". The University of Chicago Law Review, Chicago. p. 297-321, 2017. p. 298). 
oportunidades de aprendizado incremental pela prática mais longeva de uma determinada política pública.

Em síntese, reconcilia-se normatividade e gestão ${ }^{30}$, com o crivo judicial acontecendo a partir de um cenário enriquecido não só pela interpretação antes empreendida pela Administração, como também com os dados factuais relacionados aos resultados da conduta sindicada.

A proposta ganha particular relevância no cenário de complexidade e incertezas em que se desloca a Administração Pública nessa segunda década do século XXI. Se planejar é um reclamo constitucional, e se a ação pública deve ter oportunidade no exercício desse desenho de ação de experimentar, no exercício da incorporação de valores novos; é preciso que a refutação dessas estratégias inovadoras se dê em bases mais objetivas - e não a partir da percepção subjetiva de um agente controlador que, crendo ser capaz de antever todo o leque de possibilidades de ação postas à Administração Pública, imagina-se capaz de indicar uma única e totalmente certa linha de conduta.

Igualmente relevante será o emprego da deferência para neutralizar um outro risco, que é a tendência a identificar na paralisação pura e simples da Administração, uma virtude. Nessa manifestação patológica, o controlador, mais modesto que na hipótese anterior, não sabe exatamente qual seja a conduta desejável da Administração - mas ele tem íntimo convencimento do desacerto daquela ação pública sobre a qual recaiu a escolha do gestor. A certeza aqui não é positiva, mas negativa - qualquer outra solução será melhor do que a existente. O resultado pode ser ainda pior no que toca ao interesse público, eis que se paralisa a ação pública planejada em curso, sem que nada se ofereça como alternativa de ação.

Alinhados possíveis benefícios da aplicação da estratégia da deferência para o exercício do controle da Administração Pública, resta indagar: como isso instrumentaliza de maneira mais direta, a superação da problemática que provocou o presente texto, a saber, aquela da dissociação entre planejamento e orçamento?

\section{INDUÇÃO PELO VIÉS PRAGMÁTICO: COMO ATRAIR O GESTOR PÚBLICO À LÓGICA DO PLANEJAMENTO QUE ENGLOBA A EX- PRESSÃO ORÇAMENTÁRIO}

Afirmou-se no item 3 acima, a crença de que as ferramentas de indução têm expressivo papel a desenvolver no fortalecimento da lógica de que o reclamo

30 Em torno do tema da deferência, analisando especificamente a relevância dessa reconciliação entre normatividade e gestão tem-se VALLE, Vanice Regina Lírio do. Administração e políticas públicas: deferência como efeito jurídico da ação pública planejada. In: LEITE, George Salomão, STRECK, Lênio; NERY JR., Nelson (Coords.). Crise dos Poderes da República: Judiciário, Legislativo e Executivo, São Paulo: Revista dos Tribunais, 2017. 
constitucional de planejamento deva compreender a tradução dos programas de ação nos instrumentos legais aplicáveis no campo do direito financeiro. Nessa perspectiva, a proposta da outorga do signo de deferência para com as escolhas públicas antecedidas e executadas segundo o planejamento. Mas quais os elementos que permitem supor que o efeito preconizado (deferência) seja capaz de gerar maior adesão ao dever de planejamento em seu sentido mais amplo, compreendendo sua tradução no plano das finanças públicas?

O caráter de incentivo que se está aqui afirmando repousa na circunstância de que, na perspectiva do gestor público, dois riscos lhe despertam temor: a descontinuidade de suas ações, e a responsabilização.

A descontinuidade preocupa, porque muitos dos programas públicos se pretende figurem, por si como uma "marca" daquele gestor; ou ainda sua execução na íntegra é desejável para veicular uma imagem de gestor eficiente, que manteve a máquina funcionando. A par disso, descontinuidade em programas públicos, na perspectiva do gestor pode determinar a perda de timing econômico, político ou financeiro - e com isso, frustrar um relevante objetivo de governo; uma política pública na qual ele firmemente acredita socialmente eficaz.

Suspensões ou interrupções de programas públicos tem possíveis efeitos matriciais adversos sobre outras políticas públicas - o que pode gerar um desastroso efeito dominó no conjunto de ações em curso. Existe ainda o inequívoco custo financeiro da paralisia de iniciativas já em andamento. Descontinuidade é o pesadelo do gestor público no exercício do mandato.

De outro lado, a responsabilização - que se porá com mais frequência depois do término da gestão, quando até mesmo o acesso aos dados materiais pode ser mais difícil - é igualmente um fantasma, especialmente com a intensificação dos controles públicos, com o alcance de patrimônio pessoal, e ainda, inelegibilidades.

A incorporação da lógica da deferência como aqui se propõe, com a presunção de adequação reforçando a lógica da continuidade - e não no bloqueio - mitiga o risco de interrupção, o que permite identificar um primeiro impulso de indução em favor da ação planejada no seu todo, com o devido reflexo orçamentário. Mesmo particulares virtualmente envolvidos em determinada iniciativa pública podem ter interesse em concorrer para o aperfeiçoamento do planejamento, na medida em que também a eles interessa incrementar o grau de estabilidade da relação que se venha eventualmente a desenvolver com a Administração.

Mas é no campo da prevenção à responsabilização que a deferência pode se apresentar como poderoso elemento de indução à ação planejada.

Cenários de alta complexidade como este em que se desloca a Administração Pública envolvem necessariamente maior risco, intensificando o dilema entre a ação (potencialmente reprovável) e a letargia. 
Mais ainda, em tempos de incerteza, e na seara de relações de longo prazo, o foco no resultado é decerto relevante - mas este resultado pode exigir tempo para sua concretização, e com isso tem-se por sujeito a um maior número de contingências. $A$ par disso, especialmente em se cuidando da Administração Pública, os fins não devem justificar nem tampouco condenar os meios - ambos os vetores da conduta administrativa são igualmente relevantes na perspectiva estritamente constitucional. A lógica de que a Administração Pública disponha de uma única "bala de prata", que deve matar o monstro que ameaça o interesse público desconsidera o muito que pode se interpor entre o petardo e o seu destino.

Deferência para com a escolha administrativa precedida de planejamento e executada segundo essa mesma premissa valoriza o exercício de racionalidade administrativa, mas deixa espaço ainda para a experimentação; compromete o gestor com o desenho de ação que ele mesmo traça e induz um exercício de controle dialógico, que tem por subproduto, ainda nas hipóteses em que a conclusão final seja pelo reprocho à ação administrativa, o aperfeiçoamento dessa mesma atividade. Isso porque se o exercício crítico é de se fazer à luz das razões e métrica apresentadas pela Administração, o juízo de reprovação evidenciará para esse mesmo aparato, onde se teve uma avaliação fática ou jurídica inadequada, e permitirá a reconfiguração para futuro.

É certo que a incorporação da lógica da deferência propõe como pauta reflexiva, a determinação dos atributos da ação administrativa que permitam qualifica-la como planejada. Esse será por excelência, campo para a contribuição criadora dos órgãos de controle - mas a partir de uma perspectiva que veja essa mesma função como sistema, operando de maneira articulada ${ }^{31}$, e não concorrencial.

A lógica constitucional, relacionando planejamento e finanças públicas, externa um compromisso não só com a eficiência, mas também com a controlabilidade objetiva do agir do poder. Esse o objetivo almejado com a proposição da reconciliação entre planejamento e orçamento, pela via da deferência para com as escolhas administrativas a eles reverentes. A presença da Administração Pública por si só, não parece suficiente para sustentar inteiramente, a legitimidade de uma escolha pública - mas ela tampouco pode ser o bastante para atrair sobre ela, o signo da suspeita.

\section{REFERÊNCIAS}

BATISTA JÚNIOR, Onofre Alves. O princípio constitucional da eficiência administrativa. 2. ed. Belo Horizonte: Fórum, 2012.

\footnotetext{
31 É de Dromi a indicação de que a modernização do controle público aponta para uma responsabilidade compartilhada, que reclama articulação entre as ações e instância de controle, de molde a que possam elas igualmente se ajustarem às regras de eficácia, transparência e economia na gestão da coisa pública (DROMI, R. Modernización del control público. Madrid-Mexico: Hispania Libros, 2005. p. 43.).
} 
BERCOVICl, Gilberto; SIQUEIRA NETO, José Francisco. O artigo 23 da Constituição de 1988 e as competências comuns. Revista brasileira de estudos constitucionais - RBEC, Belo Horizonte, Ano 2, n 6, p. 49-65, abr/jun 2008.

BRASIL. Decreto-Lei 200, de 25 de fevereiro de 1967. “Dispõe sôbre a organização da Administração Federal, estabelece diretrizes para a Reforma Administrativa e dá outras providências", publicado no DOU de 27.2.1967.

BRASIL. Lei 12.305 de 12 de agosto de 2010, de 2 de agosto de 2010. "Institui a Política Nacional de Resíduos Sólidos; altera a Lei no 9.605, de 12 de fevereiro de 1998; e dá outras providências", publicado no DOU de 3.8.2010.

BRASIL. Lei 12.608 de 10 de abril de 2012. "Institui a Política Nacional de Proteção e Defesa Civil - PN, PDEC; dispõe sobre o Sistema Nacional de Proteção e Defesa Civil - SINPDEC e o Conselho Nacional de Proteção e Defesa Civil - CONPDEC; autoriza a criação de sistema de informações e monitoramento de desastres; altera as Leis nos 12.340, de 1 o de dezembro de 2010, 10.257, de 10 de julho de 2001, 6.766, de 19 de dezembro de 1979, 8.239, de 4 de outubro de 1991, e 9.394, de 20 de dezembro de 1996; e dá outras providências", publicado no DOU de 11.4.2012

BRASIL. Lei Complementar 101 de 4 de maio de 2000. “Estabelece normas de finanças públicas voltadas para a responsabilidade na gestão fiscal e dá outras providências", publicada no DOU de 5.5.2000.

BRASIL. Lei Complementar 159 de 19 de maio de 2017. "Institui o Regime de Recuperação Fiscal dos Estados e do Distrito Federal e altera as Leis Complementares no 101, de 4 de maio de 2000, e no 156, de 28 de dezembro de 2016", publicado no DOU de 22.5.2017.

BRASIL, Supremo Tribunal Federal. RE 592581, Relator(a): Min. RICARDO LEWANDOWSKI, Tribunal Pleno, julgado em 13/08/2015, ACÓRDÃO ELETRÔNICO REPERCUSSÃO GERAL - MÉRITO DJe-018 DIVULG 29-01-2016 PUBLIC 01-02-2016.

BRASIL. Supremo Tribunal Federal. ADI 5633, Relatora a Min. Rosa Weber - ainda em processamento, sem decisão proferida.

DROMI, Roberto. Modernización del control público. Madrid-Mexico: Hispania Libros, 2005.

JORDÃO, Eduardo. Controle judicial de uma Administração Pública complexa: a experiência estrangeira na adaptação da intensidade do controle. São Paulo: Malheiros Editores, 2016.

MARQUES NETO, Floriano de Azevedo; DE PALMA, Juliana Bonacorsi. Os sete impasses do controle da administração pública no Brasil. In: PEREZ, Marcos Augusto; SOUZA, Rodrigo Pagani de. Controle da administração pública. Belo Horizonte: Fórum, 2017, p. 21-38.

MASCARENHAS, Rodrigo Tostes de Alencar. O medo e o ato administrativo. Revista Direito do Estado. n²89, Ano 2016. Disponível em: <http://www.direitodoestado.com.br/colunistas/rodrigo-tostes-mascarenhas/o-medo-e-o-ato-administrativo>. Acesso em: 01 set. 2017. 
MINDLIN, Betty. Introdução - o conceito de planejamento. In: (Org.). Planejamento no Brasil. 6. ed. São Paulo: Perspectiva, 2010.

MORAND, Charles Albert. Le droit néo-moderne des politiques publiques, Paris: Librarie Génerale de droit et de jurisprudence, 1999.

MOREIRA NETO, Diogo de Figueiredo. Novas mutações juspolíticas. Em memória de Eduardo García de Enterría, jurista de dois mundos. Belo Horizonte: Fórum, 2016.

PUPPIM DE OLIVERIA, José Antonio. Desafios do planejamento em políticas públicas: diferentes visões e práticas. Revista de Administração Pública-RAP, Rio de Janeiro, vol. 40, n. 2, p. 273-288, mar./abr. 2006.

RATTNER, Henrique. Planejamento e bem-estar social. São Paulo: Perspectiva, 1979.

SCALIA, Antonin. Judicial deference to administrative interpretations of law. Duke Law Journal, Durham, n. 3, p. 511-521, jun. 1989.

SUNDFELD, Carlos Ari. Crítica à doutrina antiliberal e estatista de direito administrativo. In:

Direito administrativo para céticos. 2. ed. São Paulo: Malheiros.

SUNSTEIN, Cass; VERMEULE, Adrian. Interpretation and institutions. Michigan Law Review, Michigan, vol. 101, n. 4, p. 885-951, 2003.

SUNSTEIN, Cass; VERMEULE, Adrian. The Unbearable Rightness of "Auer". The University of Chicago Law Review, Chicago, p. 297-321, 2017.

THALER. Richard H.; SUNSTEIN, Cass. Nudge: Improving decisions about health, wealth and happiness. New Haven \& London: Yale University Press, 2008.

UNITED STATES. Supreme Court of the United States. Chevron U.S.A., Inc. v. Natural Resources Defense Council, Inc., 467 U.S. 837 (1984).

VALLE, Vanice Regina Lírio do. Função administrativa e orçamento: o espaço negligenciado de efetividade dos direitos fundamentais. In: GUERRA, Sérgio e FERREIRA JR., Celso Rodrigues (orgs.). Direito Administrativo. Estudos em homenagem ao Professor Marcos Juruena Villela Souto. Belo Horizonte: Fórum, 2015. p. 398-418.

VALLE, Vanice Regina Lírio do. Dever constitucional de enunciação de políticas públicas e autovinculação: caminhos possíveis de controle jurisdicional. Fórum Administrativo, Belo Horizonte, v. 82, p. 7-19, 2007.

VALLE, Vanice Regina Lírio do. PULCINELLI, Eliana; MANEIRO, Renata de Marins Jaber (Coord). Contestação, persuasão e consenso no STF: construindo um constitucionalismo democrático. Rio de Janeiro: Gramma, 2016.

VALLE, Vanice Regina Lírio do. Administração e políticas públicas: deferência como efeito jurídico da ação pública planejada. In: LEITE, George Salomão, STRECK, Lênio; NERY JR., Nelson (Coords.). 
Crise dos Poderes da República: Judiciário, Legislativo e Executivo. São Paulo: Revista dos Tribunais, 2017.

VALLE, Vanice Regina Lírio do. Novo Regime Fiscal, autonomia financeira e separação de poderes: uma leitura em favor de sua constitucionalidade. Revista de Investigações Constitucionais, Curitiba, vol. 4, n. 1, p. 227-258, jan./abr. 2017.

WAHRLICH, Beatriz. A reforma administrativa no Brasil: experiência anterior, situação atual e perspectivas: uma apreciação geral. Revista de Administração Pública - RAP, Rio de Janeiro, vol. 18, n. 1, p. 49-59, 1984. 